\title{
A Study on the Noise and Vibration Analysis of 200kW PMSM for Electric Propulsion Ship
}

\author{
Yang-Uk Cho *, and Gyu-Hong Kang *
}

\begin{abstract}
This paper presents one of the methods for design to reduce the noise and vibration of $200 \mathrm{~kW}$ motor for electric propulsion ship. One of the important factors affecting vibration of the motor is the resonance. The natural frequency and natural mode of the $200 \mathrm{~kW}$ motor is analyzed by using FEM tool and impact test equipment to avoid the resonance. Also, compare FEM result with impact test result to make a reliable FE model of $200 \mathrm{~kW}$ motor. In order to find out the effect of the noise and vibration of the motor by electromagnetic excitation force, conduct electromagnetic-structure coupled analysis. These characteristics are much useful to design $200 \mathrm{~kW}$ motor for electric propulsion ship
\end{abstract}

Keywords: Natural frequency, Natural mode, Resonance, Tangential force, Radial force, Structural vibration, Electromagnetic force, Radiated noise, Boundary element method

\section{Introduction}

The Study of the electric motor has been conducted due to $\mathrm{CO}_{2}$ emission regulation policy and its increasing trend capacity. However, the increasing noise and vibration problem is occurred according to increasing the electric motor capacity. Focus on design of the increasing electrical characteristics of the motor for high output, the noise and vibration that occurs will affect the system. To reduce the vibration and noise, it needs to analyze the characteristics of the motor causing the noise and vibration.

The basic function of the motor is converting electrical energy into mechanical energy. In the process of converting energy, the electromagnetic force is generated. The radial electromagnetic force is the greatest effect on the noise and vibration of the motor during operation [1]-[2]. Particularly the more noise and vibration will occur when the rotation frequency of the electric motor leads to the resonance. William was analyzed by dividing the electrical part and mechanical part of noise and vibration source, and dealing with resonance, critical speed, and rotating unbalance [3][5]. The vibration caused motor noises can be reduced by changing of design avoiding the resonance and electromagnetic forces that occur in the motor operating condition. Thus, the vibration characteristic and the natural frequency analysis of the motor are very important.

In this paper, $200 \mathrm{~kW}$ motor for electric propulsion ship

* $\quad$ Electric \& Electronic Research Division, Korea Marine Equipment Research Institute, Korea. (kang@komeri.re.kr)

Received 25 October 2014; Accepted 15 November 2014 was analyzed to design the low vibration motor. Finite element method (FEM) analysis and impact test was carried out to find the natural frequency and the natural mode. And compare FEM analysis result with impact test result to obtain a reliable FE model of the $200 \mathrm{~kW}$ motor. On the basis of the validated FE model, electromagnetic-structure coupled analysis was carried out in order to see effect on the vibration of the motor by electromagnetic force. The low vibration motor will be designed by comparing the experimental result with numerical results. And the vibration characteristics of $200 \mathrm{~kW}$ motor will be based testing on the improvements.

\section{Natural Frequency Analysis}

Analysis model of the $200 \mathrm{~kW}$ motor for electric propulsion ship is shown in Fig. 1 and the specifications are shown in Table 1. FE model mesh shown in Fig. 1 used 3D solid element composed of 160,901 hexa elements and 1,854 penta elements.
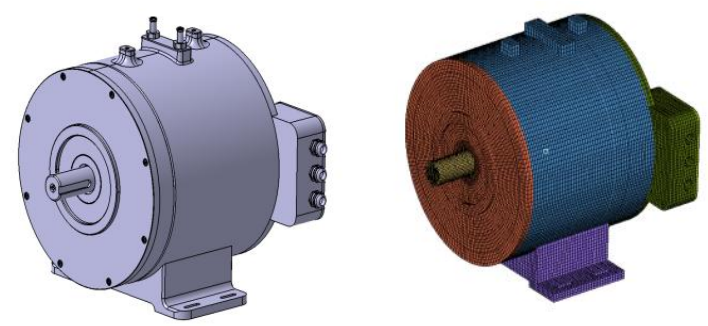

Fig. 1. 3D and FE model of 200kW motor 
Table 1. Specifications of the $200 \mathrm{~kW}$ motor

\begin{tabular}{|c|c|}
\hline ITEM & Specification \\
\hline Rated Speed $[\mathrm{rpm}]$ & 3500 \\
\hline Rated Torque $[\mathrm{Nm}]$ & 555.28 \\
\hline Rated Current $\left[\mathrm{A}_{\mathrm{rms}}\right]$ & 255 \\
\hline Poles / Slots & $16 / 18$ \\
\hline Air-gap length $[\mathrm{mm}]$ & 2 \\
\hline Stator diameter $[\mathrm{mm}]$ & 220 \\
\hline
\end{tabular}

FEM analysis and impact test were performed to analyze the natural frequency and the natural mode. And FE model of $200 \mathrm{~kW}$ motor parts was verified by comparison FEM analysis with impact test result. Commercial program Nastran was used for modal analysis and LMS Test. Lab was used for impact test. FE model is shown in Fig. 1 and impact test equipment is shown in Fig. 2.

Impact test equipment was composed with LMS Test.Lab, accelerometer and impact hammer. And impact test data acquisition setting was shown in Table 2. The sampling frequency was set at $3200 \mathrm{~Hz}$ since excitation frequency of the impact hammer is $3200 \mathrm{~Hz}$. And use window function in order to reduce leakage error.
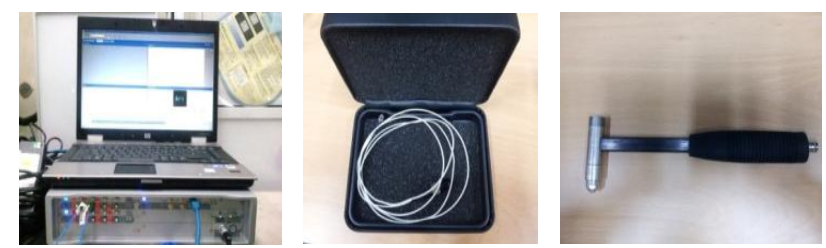

Fig. 2. Impact test equipment

Table 2. Impact test data acquisition setting

\begin{tabular}{|c|c|}
\hline ITEM & Specification \\
\hline Sampling frequency $[\mathrm{Hz}]$ & 3200 \\
\hline Resolution $[\mathrm{Hz}]$ & 0.7592 \\
\hline Record length $[\mathrm{s}]$ & 1.317 \\
\hline Averaging & 3 times \\
\hline Window function & $\begin{array}{c}\text { Input }- \text { Force exponential/ } \\
\text { Output }- \text { Exponential }\end{array}$ \\
\hline
\end{tabular}

Impact test was performed about $200 \mathrm{~kW}$ motor parts on the sponge to make condition of free DOF.

Impact test geometry of the front cover, one of the 200kW motor parts, was shown in Fig. 3 and composed of the 56 nodes. Impact test was carried out about 56 nodes and 3 times average per one node.

FRF (Frequency response function) was shown in Fig. 6 at self-excitation point on the front cover. And natural mode was shown in combination with the natural vector of each node. Fig. 4 shows natural mode shape of the front cover. There are bending mode at first mode $(443 \mathrm{~Hz})$ and second mode $(767 \mathrm{~Hz})$.

Also, the modal analysis was performed using FEM tool. The result was shown in Fig. 5. It was confirmed that the same mode shape of the impact test result and FEM analysis result. FE model of the $200 \mathrm{~kW}$ motor was verified by comparison with impact test result.

Fig. 6 shows the FRF at self-excitation point on the front cover. It can be seen that impact test result and FEM analysis result are relatively well matched.
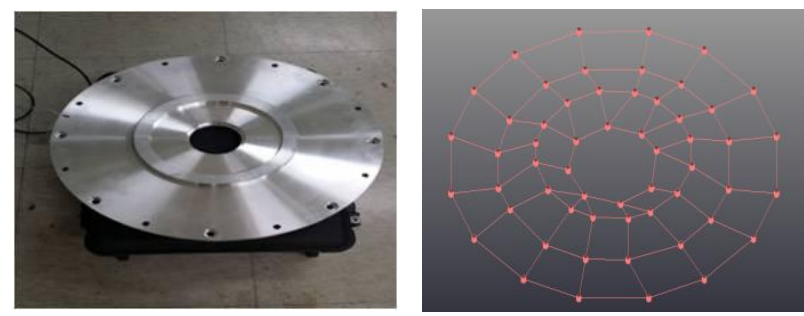

Fig. 3. Impact test geometry of the front cover
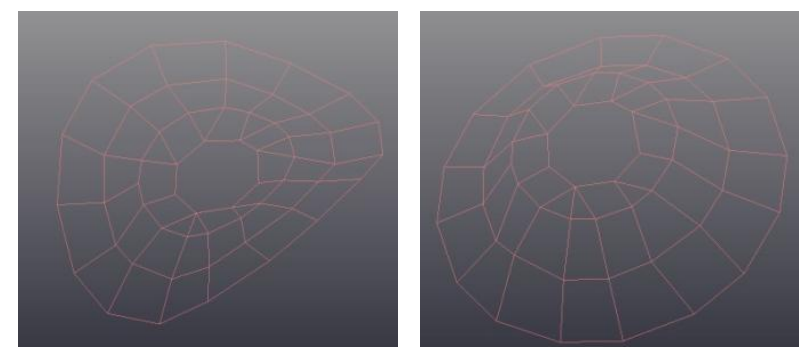

Fig. 4. First and second natural mode shape by impact test
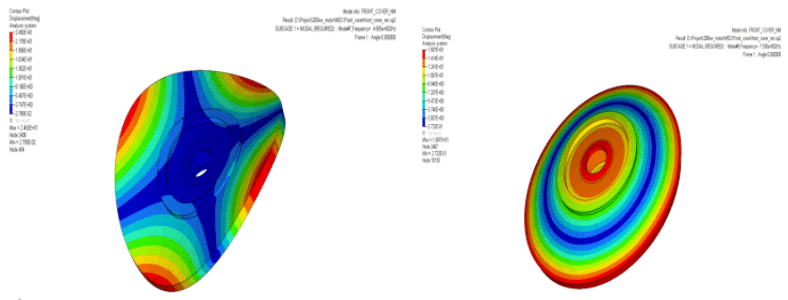

Fig. 5. First and second natural mode shape by FEM

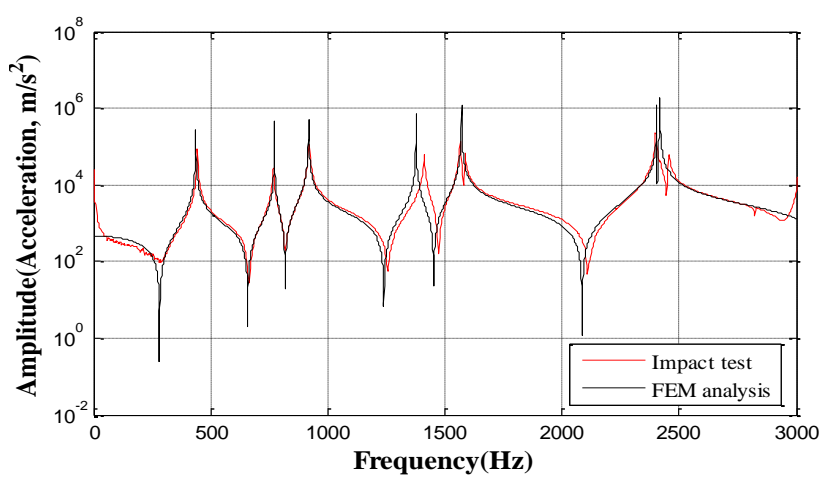

Fig. 6. FE model of the $200 \mathrm{~kW}$ motor and front cover

Even more impact test and FEM analysis was performed 
about other motor parts and the first and second natural frequency was shown in Table 3. It seems that the result of the impact test and FEM analysis was almost coincided.

Table 3. Natural frequency of the $200 \mathrm{~kW}$ motor

\begin{tabular}{|c|c|c|c|c|}
\hline \multirow{2}{*}{ ITEM } & \multicolumn{2}{|c|}{ Experiment(Hz) } & \multicolumn{2}{c|}{$\begin{array}{c}\text { FEM } \\
\text { Analysis(Hz) }\end{array}$} \\
\cline { 2 - 5 } & $\begin{array}{c}1^{\text {st }} \\
\text { mode }\end{array}$ & $\begin{array}{c}2^{\text {nd }} \\
\text { mode }\end{array}$ & $\begin{array}{c}1^{\text {st }} \\
\text { mode }\end{array}$ & $\begin{array}{c}2^{\text {nd }} \\
\text { mode }\end{array}$ \\
\hline Front cover & 443 & 767 & 436 & 772 \\
\hline Housing & 390 & 537 & 369 & 513 \\
\hline Rear cover & 356 & 416 & 354 & 420 \\
\hline Shaft & 1208 & 2829 & 1211 & 2824 \\
\hline
\end{tabular}

\section{Electromagnetic Analysis}

The electromagnetic characteristic of the $200 \mathrm{~kW}$ motor was applied to a finite element analysis in this study. Changing of the air-gap flux density was investigated to effect vibration of the motor by electromagnetic force.

Fig. 7 shows magnetic flux density distribution and magnetic flux line about $1 / 2$ model of 16 poles and 18 slots. Segmentation of permanent magnetic, shape of a magnetic circuit and combination of the pole and slot were optimized through design of experiment to minimize cogging torque and torque ripple.

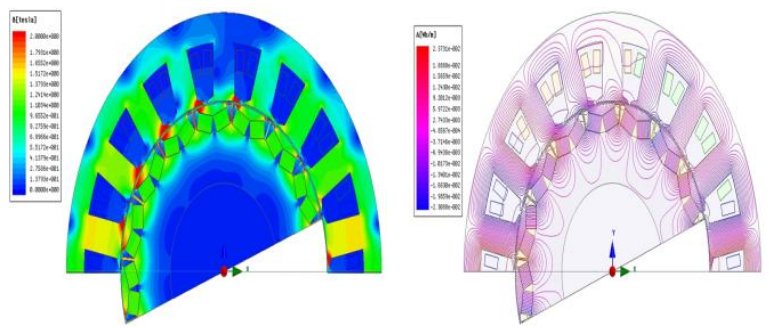

Fig. 7. Magnetic flux density and magnetic flux line

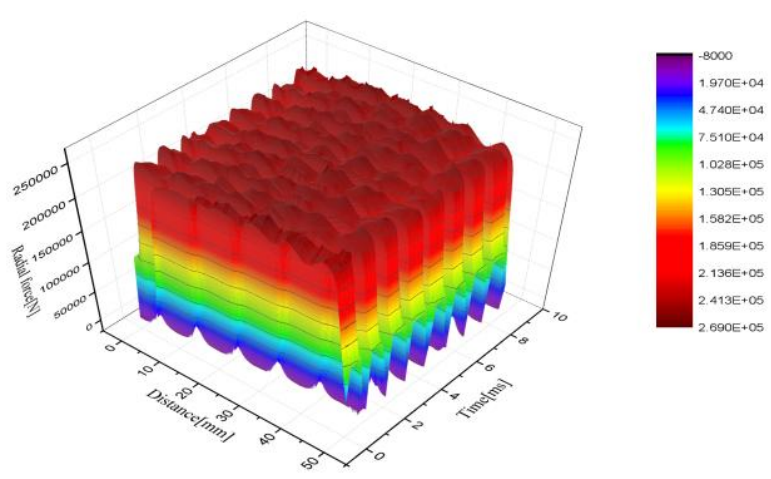

Fig. 8. Electromagnetic force distribution according to time and distance
Fig. 8 shows that electromagnetic force according to time and distance of teeth. Unbalanced magnetic forces acting on the rotor surface was calculated with the Maxwell stress tensor and the radial and tangential force is (1) and (2) [6].

$$
\begin{gathered}
F_{r a d}\left(\theta_{s}, t\right)=\frac{1}{2 \mu_{0}}\left[B_{r}{ }^{2}\left(\theta_{s}, t\right)-B_{\theta}{ }^{2}\left(\theta_{s}, t\right)\right] \\
F_{\text {tan }}\left(\theta_{s}, t\right)=\frac{1}{\mu_{0}}\left[B_{r}\left(\theta_{s}, t\right) \times B_{\theta}\left(\theta_{s}, t\right)\right]
\end{gathered}
$$

where, $F_{\text {rad }}$ is radial component of force density, and $F_{\text {tan }}$ is tangential component. $B_{r}$ and $B_{\theta}$ are the radial and tangential component of the air-gap flux density. $\mu_{0}$ is magnetic permeability at free space. $\theta_{s}$ is angular position and $t$ is time. It was assumed that electromagnetic force between rotor surface and teeth will occur through action and reaction at air gap. Input source of structure analysis is calculated the sum of the electromagnetic force every step.

Fig. 9 shows the radial and tangential force in frequency domain. Looking in the frequency domain, there is a frequency of the electromagnetic force $(933 \mathrm{~Hz})$ in both radial and tangential force.
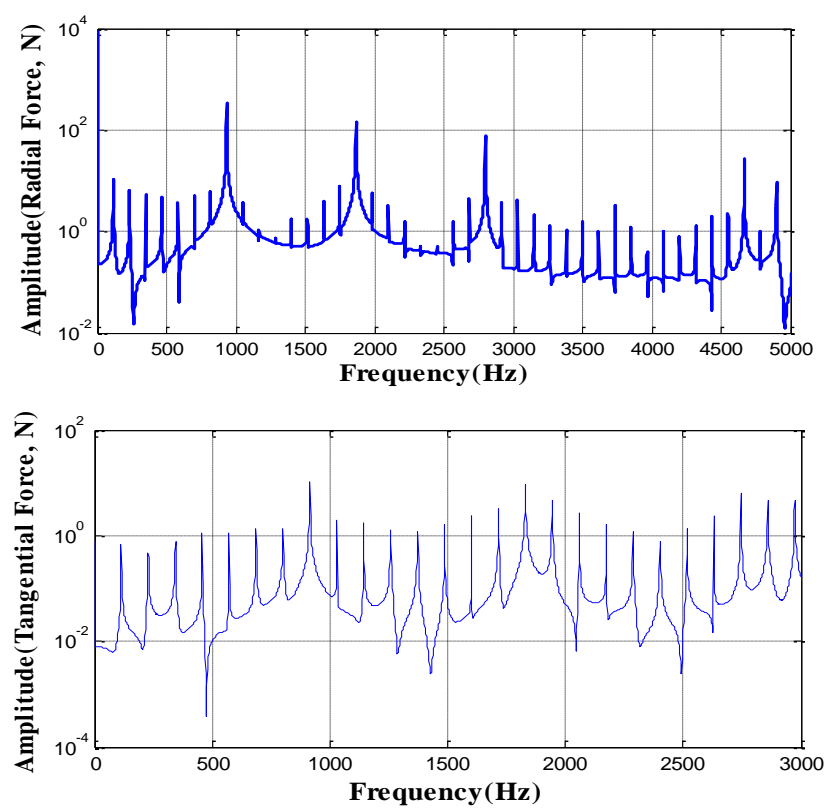

Fig. 9. Frequency domain of the radial and tangential force

\section{Structure Vibration Analysis}

Frequency response analysis was carried out using electromagnetic force calculated by electromagnetic analysis. It was assumed that the electromagnetic force is acting on the teeth surface. So, structural excitation force was applied to the nodes of teeth surface. 
Frequency response at a node of housing surface was shown in Fig. 10. The frequency of electromagnetic force and the multiple component of the rotating frequency appear significantly.

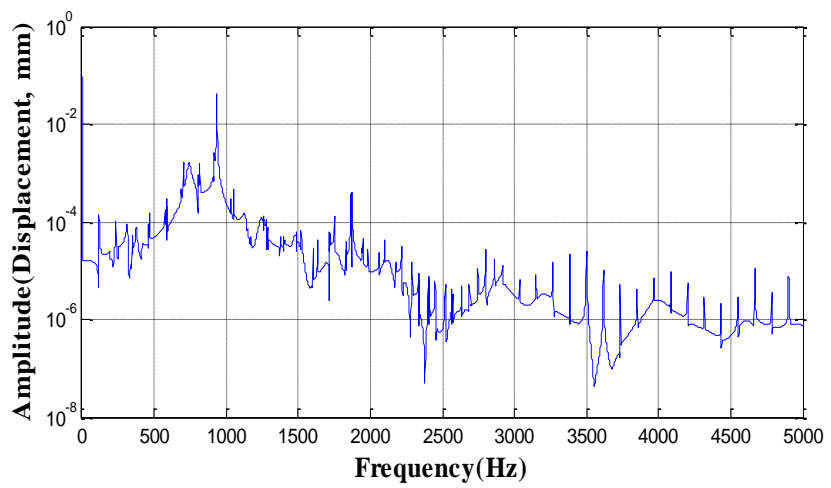

Fig. 10. The caption for a figure must follow the figure

The RMS (Root mean square) value of the vibration at the housing is $2.10 \mathrm{um}$ and peak to peak value is $91.7 \mathrm{um}$.

To compare the magnitude of the motor vibration generated by electromagnetic force, the magnitude of the frequency response at the nodes of the motor surface was shown in Table 4.

Table 4. Magnitude of the vibration at the motor surface

\begin{tabular}{|c|c|c|}
\hline \multirow{2}{*}{ ITEM } & \multicolumn{2}{|c|}{ Specification } \\
\cline { 2 - 3 } & RMS (um) & Peak to Peak (um) \\
\hline Front cover & 1.30 & 62.7 \\
\hline Housing & 2.10 & 91.7 \\
\hline Rear cover & 0.46 & 23.0 \\
\hline Shaft & 3.50 & 136 \\
\hline Front bearing & 0.57 & 22.9 \\
\hline Rear bearing & 0.38 & 14.0 \\
\hline
\end{tabular}

It can be seen that the more vibration occur at shaft, the next is housing. The motor vibration occur entirely front part of the motor more than rear part of the motor.

\section{Radiated Noise Analysis}

The radiated noise analysis of the $200 \mathrm{~kW}$ motor is conducted by boundary element method. The results of the structure vibration by electromagnetic force are given as a boundary condition. Boundary element model was composed of outer surface of the motor, base plane and field point. Symmetry plane was modeled for reflection of bottom and field point was modeled as shown in Fig. 11 according to ISO 3744.

The radiated noise distribution by electromagnetic force was shown in Fig. 12. Looking at the sound pressure distribution in field point, it can be seen that it has occurred up to $86.1 \mathrm{~dB}(\mathrm{~A})$.

Fig. 13 shows that $1 / 3$ octave band of sound pressure level at the field point. The sound pressure level was generally higher in the high-frequency band and $1000 \mathrm{~Hz}$ band was confirmed to appear high. The electromagnetic force $(933 \mathrm{~Hz})$ is the main component in the $1000 \mathrm{~Hz}$ band.

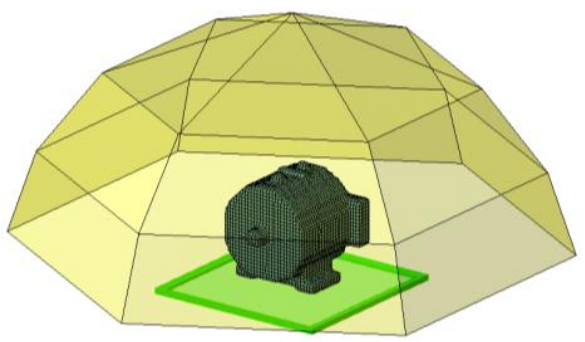

Fig. 11. Field point mesh according to ISO 3744

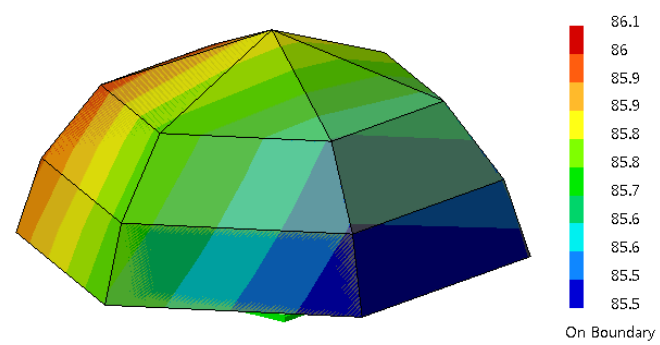

Fig. 12. Sound pressure distribution over the field point mesh

Sound Pressure Level

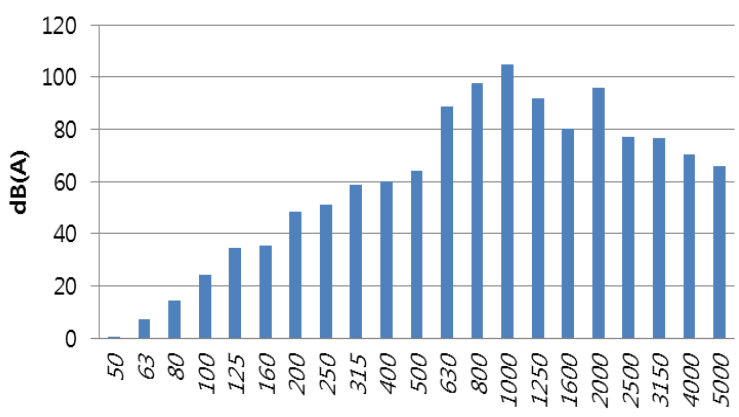

$1 / 3$ Octave band

Fig. 13. 1/3 Octave band of sound pressure level

\section{Conclusion}

In this paper, the method for design to reduce the noise and vibration of the $200 \mathrm{~kW}$ motor for electric propulsion ship was presented by FEM analysis and impact test. Also structural vibration analysis was carried out to see the effect 
of the noise and vibration of the motor by electromagnetic excitation force.

To find out the resonance of the motor, the FEM analysis and impact test was performed. A reliable FE model was obtained by comparison the FEM analysis result and the impact test result. Analysis of whether or not the resonance with the electromagnetic excitation force was performed. The problem by the resonance was not detected.

The radial and tangential force acting on the teeth was calculated by electromagnetic analysis. The $933 \mathrm{~Hz}$ component of the radial and tangential force appears. Looking at the structural vibration analysis, there is a 933 $\mathrm{Hz}$ component, too. Compared to the magnitude of the vibration of the motor for each part, the most significant vibration occurred in the shaft and the more vibration occurs in front parts than rear parts. Thus, it is recommended to adjust the stiffness of the front part of the motor.

In the radiated noise analysis, $1000 \mathrm{~Hz}$ band component appear high. The electromagnetic force $(933 \mathrm{~Hz})$ is the main component in the $1000 \mathrm{~Hz}$ band. In order to reduce the noise and vibration of the motor should be reduced 933 $\mathrm{Hz}$ component which is frequency of the electromagnetic excitation force.

The analysis of $200 \mathrm{kw}$ motor vibration and radiated noise by electromagnetic excitation force was approached numerically, but it needs to be verified experimentally.

\section{Acknowledgements}

This work was supported by SW Convergence Components and Materials Technology Development (11043799) funded by Ministry of Trade, industry \& Energy.

\section{References}

[1] W. H. Kim, I. H. Hong and J. T. Chung, "A study on noise reduction for the driving system of a forklift," Transactions of the Korean society for noise and vibration, vol. 18, no. 1, pp.80-86, 2008.

[2] H. J. Lee, J. H. Kwon, C. M. Lee, G. Y. Hwang and S. M. Hwang, "Analysis of noise characteristics considering magnetic force of IPM motor," KSNVE, vol. 19, no. 5, pp. 439-446.

[3] S. P. Verma and A. Balan, "Determination of radial force in relation to noise and vibration problems of squirrel-cage induction motors," IEEE Transactions on Energy Conversion vol. 9, no. 2, pp. 404-412, 1994.

[4] R. William, "An analytic approach to solving motor vibration problems" IEEE., vol. 36, pp. 1476-1480, 2000.

[5] D. G. Dorell, "Calculation of unbalanced magnetic pull in small cage induction motors with skewed rotors and dynamic rotor eccentricity," IEEE Transaction of Energy Conversion, vol. 11, no. 3, pp. 483-488, 1996.

[6] J. F. Gieras, C. Wang and J. C. Laj, "Noise of Polyphase Electrical Motors," Taylor \& Francis Group, ISBN 01-82472381-3

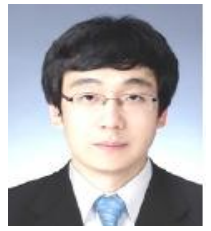

Yang-Uk Cho received B.S degree in mechanical engineering from Pusan National University. He is researcher in Korea Marine Equipment Research Institute. His research interests are noise and vibration.

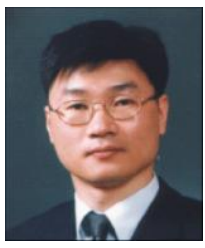

analysis.
Gyu-Hong Kang received M.S and Ph.D. degree in electrical engineering from Changwon National University. $\mathrm{He}$ is general manager in Korea Marine Equipment Research Institute. His research interests are electrical machine and FEM 